recession of the extra-galactic nebulæ, partly because, as a bare fact of experience, that is not a motion at all but a characteristic of spectrum lines, only interpreted as a motion when we have accepted certain rather detailed terms of expression of experience; and even then, as the present disagreement among astronomers shows, not inevitably so interpreted. But I ignore it also because, even if it is taken into account, it does not alter the fact that motions show a one-way tendency, but simply indicates that the tendency is in one direction in some circumstances and in the opposite one in others ; it does not make the phenomenon of motion indifferent to the direction of time as the present laws of motion do. The indications of bare experience can be represented by the simple idealized situation I pictured earlier. Place two bodies at different points in an otherwise empty universe. They will move in one direction, and not the opposite one, with respect to one another; and they will tend towards the same and not more widely divergent temperatures.

This common one-wayness is, in fact, shown in almost all our theories of cosmic evolution, characterizing the motions as well as the temperature phenomena of the universe. Laplace's nebular hypothesis, for example, depicted a primitive diffuse nebula evolving gradually into a complex organiza. tion of many bodies, and, quite apart from the laws of temperature, it provided no possibility of the course of events occurring in the reverse direction. Generalizing such ideas, Herbert Spencer's famous definition of evolution, concerned with matter and motion alone, included onlv a one-way process from the homogeneous to the heterogeneous. Even in detailed phenomena, such as the direction of revolu. tion of the planets round the sun, we recognize that. whatever the laws of motion may allow, the planets do, in fact, go in a partisular direction, and wo do not regard it as possible that they will change to the opposite one. The actual, as contrasted with the possible, course of events is uni-directional. Somewhere, in building up our structure of laws of motion from the observed facts, we have introduced a liberty of movement which is not in fact taken advantage of, whereas in building up our structure of laws of temperature from the observed facts we have introduced no such liberty. The difference lies in our terms of expression of experience, and not in bare experience itself, and we must look for it there.

2 "Relativity, Thermodynamics and Cosmology" (Oxford University Press, 1934).

- Math. Ann., 67, 355 (1909). The theory has been expounded very clearly by M. Born in three articles in Phys. Z., 22 (1921).

s Phil. Mag., iv, 4, 358 (1852).

( $T$ o be continued.)

\section{SOIL STERILIZATION}

$\mathrm{I}^{\mathrm{N}}$ horticulture, as in other industries, the War has focused attention on ways and means which before 1939 had not received the notice they deserved. Among them is soil sterilization as a factor in food production. How to produce the greatest amount of good food has become an urgent problem for Great Britain, and there is little reason for believing that this need will be much less pressing for some years to come. To produce the quantity and quality of food we require, five things are necessary. Site, soil and cultivation must be suitable, the choice of variety must be correct and pests and diseases must be controlled. All these are important, but not every one has received proper consideration. Pests and diseases, for example, not only cause serious losses in food production, but they also waste time, labour and materials. Thus, by employing measures for the control of pests and diseases, a higher yield per plant can be obtained with greater economy than by merely increasing the number of plants.

The more intensive the system of cropping, the more likely is it that disorders will occur and the more necessary it becomes to prevent their arising. It is not surprising, therefore, to find that the demands of war have focused attention on problems of soil hygiene in the most intensive system of all, the production of crops under glass. Growers have found that yields fall off and soil pests and diseases assume serious proportions unless the soil is partially sterilized by the periodic use of heat or chemicals.

The sterilization of soils used under glass is necessary for either of two reasons. In the case of pot plants, for which virgin soil is almost always used, sterilization kills the pests and diseases normally existing in the soil. In the case of glasshouse borders which have carried the same main crop year after year and become 'soil-sick', partly through the accumulation of various pathogenic organisms and partly due to biological and chemical unbalance, sterilization is necessary to restore the resulting loss in fertility.

Cleaning up the soil by sterilization is fast becoming an indispensable routine practice under glass, and to meet the situation war agricultural executive committees have recently added to their machinery pools, apparatus for the steam sterilization of glasshouse soils. In cases where steam sterilization is not practicable chemical sterilizing agents, such as formaldehyde, are being increasingly used. Thus, the time is ripe for consideration of the methods and problems of soil sterilization, and with this in view a joint meeting for the discussion of the subject was held on April 19, between the Society of Chemical Industry (Microbiological Panel of the Food Group and the Agricultural Group) and the Association of Applied Biologists.

Dr. W. F. Bewley discussed the general aspects of the subject. Soil sickness and the depredations of eelworms were problems which, in the early years of this century, faced the glasshouse growers in the Lea Valley and elsewhere. They found by empirical methods that if the temperature of sick or infested soil was raised to $100^{\circ} \mathrm{C}$. for a sufficient length of time, the harmful organisms were killed and fertility restored. The commonest method employed for glasshouse borders was to force steam into the soil to a depth of 12 in. or more by means of perforated pipes or an inverted tray. At first, pressures of $30-40 \mathrm{lb}$. per square inch were used, and steaming was carried on for 1-2 hr.; to-day pressures of $80 \mathrm{lb}$. or more are employed and steaming is for 20-30 min. only. For small quantities of soil, baking was commonly practised in earlier years. With this method, however, patchy heating and 'over-sterilization' are dangers, although if the soil is moderately wetted before it is baked the danger is reduced. Before use, baked soil must be left 4-6 weeks "to recover".

Low-pressure steaming is a method rapidly coming into favour. The soil is put into a perforated container which fits on to a trough of boiling water, the steam from which penetrates upwards through the soil. Electric sterilizers, in which the soil is heated either by the passage of the current through 
the soil itself, or by heaters, have also been developed. Plant growth is luxuriant following soil sterilization, and it is now clear that the fertility of glasshouse borders can be maintained over long periods if the soil is sterilized every third or fourth year and manure added from time to time to ensure good organic content and texture. As Dr. Bewley pointed out, however, although sterilization of a poor soil makes it temporarily more fertile, sterilization alone cannot change a poor soil into a rich one.

At the same time that soil sterilization methods were being developed by practical growers, critical investigations were started at the Woburn and Rothamsted Experimental Stations (1908-12). It was found that (1) weeds, weed seeds, and most soil organisms were killed at $60^{\circ} \mathrm{C}$.; (2) the nitrifying bacteria and Protozoa were also killed at $60^{\circ}$, but the ammonifying bacteria survived $100^{\circ}$ and in the absence of their enemies, the Protozoa, rapidly repopulated the soil ; (3) heating increased the amount of soluble organic and nitrogenous matter in the soil and there was a temporary excess of ammonia; (4) seedling growth was not infrequently retarded, presumably owing to the increase in the amount of soluble organic compounds, with a consequent excess production of such substances as ammonia; (5) retardation was greatest when rich soils were heated, but no direct correlation could be established between soil fertility and the degree of retardation. It was concluded that "retardation need not cause any anxiety".

From 1920 onwards, high-pressure steam won increasing favour for the sterilization of glasshouse borders in which tomatoes and cucumbers were grown. Curiously enough it did not become popular among growers who raised pot plants from seed, and so late as 1935 very few 'mixed nurseries' regularly steamed their soil. The reason for this reluctance became apparent when, in an attempt to combat soil-borne disease, sterilized soil was first used on a large scale at the John Innes Horticultural Institution. The results were disastrous in the case of one or two species and harmful in varying degrees to a number of others. At the worst, seeds did not even germinate, while commonly seedling growth was much retarded. Mr. W. J. C. Lawrence described the investigations which led to the unravelling of the complex of factors resulting in this sterilization 'check'. Clay and sand did not react to heating ; but humus gave a marked reaction. If lime was added to humus, or to a soil containing humus, before it was heated, the reaction was greater still. Prolonged heating also led to retardation. Most important of all, it was found that the addition of water-soluble phosphate (for example, superphosphate) to soil after heating counteracted the 'check' to seedling growth. From these results, and from the appearance of the plants, it was clear that the application of heat to humus resulted in its decomposition and the production of available nitrogenous compounds which, in excess, were too rich a diet for many seedlings. For example, Primula malacoides proved to be highly sensitive to soil sterilization by heating, whereas tomato and cucumber were among the most tolerant. In a few vigorously growing species the excess nitrogenous compounds actually accelerated growth even while the plant was still quite young.

It is now clear why steam sterilization, so widely used for the treatment of glasshouse borders, nad not become popular in mixed nurseries for the raising of seedlings. The particular plants used in the experi- ments at Rothamsted were relatively insensitive to the effects of heating, as are the tomatoes, cucumbers and lettuces grown in glasshouse borders; and retardation or other effects were rarely so marked as to be obvious in the absence of controls. Thus, there was no prima facie evidence that extra precautions would have to be taken for the seedlings of other species. The variable results from sterilizing different soils could also be explained, the precise outcome depending in the main on the relative proportions of humus, lime and soluble phosphate present. Soils with relatively high humus and lime and low soluble phosphate contents give the greatest retardation when sterilized. Soils with relatively low humus and lime and high soluble phosphate contents give the least retardation. In the light of these findings an improved technique of steam sterilization for seed and potting composts was worked out at the John Innes Institution, and the benefits of soil sterilization are now available for the vast majority of plant species, without any of the various evil consequences.

The practical requirements of soil sterilization by heat can now be stated in precise terms. (i) In glasshouse borders, pests and diseases occur at a considerable depth, therefore thoroughness of heating is the vital factor. The production of nitrogenous compounds in excess is not usually of serious consequence since tomatoes and cucumbers are not planted in the borders until some weeks after sterilization, and even then not as seedlings but as established plants. (ii) For seedlings and pot plants, the vital necessity is to keep down the production of nitrogenous compounds. This can be done by the efficient use of sterilizing bins in which a relatively small expenditure of heat is adequate for the thorough sterilization of the soil. The addition of superphosphate to the soil after it has been sterilized then partially immobilizes any nitrogen still in excess.

High-pressure steam sterilization has disadvantages for the small grower, of whom there are many. The locomotive boiler and steam tubing employed involve a large capital expenditure, and the apparatus is cumbersome to use. Obviously, it was worth ascertaining whether chemical substances in solution would be as efficient as steam but more convenient, especially for the small grower. Investigations were made first at Rothamsted and later at Cheshunt Experimental Stations. No chemical sterilizer proved to be as efficient all round as steam. Wetting and penetration of the soil present difficulties, and in general the action of the chemical sterilizers is more selective than steam. Thus formaldehyde, the best of the chemical agents, restores fertility well, is a good fungicide, but it is not very lethal to soil pests. Cresylic acid, on the other hand, is efficient against pests but is not very lethal to soil-borne diseases and does not restore fertility so well as formaldehyde. If the effectiveness of steam in increasing crop weight in the tomato is taken as 100 , then the figures for formaldehyde and cresylic acid may be reckoned to be less than 90 and 80 respectively. Further, whereas steaming need be done only once in every three or four years to maintain soil conditions, the chemical sterilizers must be applied every year. Improvements in the efficiency of the chemical sterilizers may be expected, however, and Mr. A. H. Dodd described the characteristics of some of the newer substances of the high-boiling phenol type.

Since the Woburn and Rothamsted experiments, practically no fundamental research has been done in 
Great Britain on soil sterilization; progress has resulted from methods and experiments of an empirical nature. A new lead has now been given by Rothamsted. Mr. H. Lees and Dr. J. H. Quastel described an ingenious method whereby studies can be made of the effects of certain chemical substances on the metabolic activity of the soil microflora. The 'perfusion unit' employed gives reproducible results, and by its aid it has been established, for example, that potassium chlorate has a selective effect on the bacteria concerned in nitrification. Oxidation of ammonia to nitrite proceeds normally; but oxidation of nitrite to nitrate is inhikited. Further, it has been possible to show that the non-production of nitrate is not a direct effect of the potassium chlorate, but results from the accumulation of nitrite. Lees and Quastel were also able to show that chlorate toxicity is greatly reduced by the addition of nitrate to the soil. Vanadium has a similar effect to chlorate, but smaller; an effect which is general instead of specific. Lees and Quastel's method seems to offer excellent possibilities for further attacks on the problem of what happens to soil when it is heated.

What then is the position of soil sterilization in horticulture to-day? By trial and error methods it has been discovered how to secure the greatest benefits with the slightest risk. Too little fundamental research has been done. For example, it is not known whether excess ammonia is the only product of heating which retards seedling growth ; indeed it is not even known whether ammonia is the chief agent concerned in retardation. The action of soluble phosphate on sterilized soil, the chemical effects of electricity in electric sterilizers, the wetting and penetration properties of chemical sterilizers, are other examples of problems awaiting investigation. On the applied side much remains to be done in the design of steam and electric sterilizing apparatus, and there is no reason why what now appears to be a remote possibility, automatic and ultra-rapid sterilization of soil on the moving belt system, should not be achieved under commercial conditions. The use of heavy gases, such as chloropicrin, is another field which awaits the attention of the tool designer as much as the soil chemist.

The main conclusions are clear. Under present and anticipated economic conditions in Britain, horticulture cannot go back to the days when infested and sick soil was tolerated in food production. Neither can it go forward, so far as soil sterilization is concerned, without the co-ordination of fundamental and applied research.

W. J. C. L.

\section{OBITUARIES}

\section{Mr. J. R. Norman}

The British Museum (Natural History) has suffered a great loss by the death at Tring at the premature age of forty-five and after a long illness of Mr. J. R. Norman, deputy keeper in the Department of Zoology.

Norman was born in London in 1898, and educated at St. Paul's School. His career was then interrupted by military service in the War of 1914-18. $\mathrm{He}$ was invalided out of the army in 1918 and resumed his education at the Imperial College of Science and Technology under the late Prof. E. W. MacBride. In 1921 he was appointed an assistant keeper in the British Museum and in 1942 was promoted to a deputy keepership. During the period of the present War he was entrusted with the charge of the branch of the British Museum at Tring.

Norman, after the retirement of the late Dr. Tate Regan, had the care of the fishes, and in this branch of zoology became the leading authority in Great Britain. He was the author of an admirable book, "The History of Fishes", and of numerous technical papers on the subject. Of these the majority deal with questions of taxonomy and morphology over a wide range of fishes and include a monograph on the Heterosomata (the flat fishes) which was published by the Trustees of the Museum. He also described collections of fishes resulting from the "Discovery", "Antarctica", "John Murray" and the "Cambridge Suez Canal" expeditions. His last work, which is on the verge of publication, is a biography of the late Dr. Charles Davies Sherborn of "Index Animalium" fame.

The rearrangement of the Fish Gallery at South Kensington and the guide book to it was his own work, and during his appointment to the charge of the Tring Museum he organized the exhibition there with great success; here he showed the width of his zoological knowledge of birds and mammals in addition to his own special subject. Both places will serve as monuments to his skill and understanding.

Norman was a fellow of the Linnean Society and of the Zoological Society, of which at the time of his death he was a vice-president.

As a colleague he was admirable from every point of view, full of enthusiasm and fertile of ideas for the good of the Museum in general. His kindly disposition made him liberal of help to others.

Owing to the complaint contracted during his military service in the War of 1914-18 Norman was never strong, but the frequent occurrence of illhealth at no time rendered him impatient nor diminished his sense of humour. He did his work and did it well and never complained. He leaves a widow and two children to whom all sympathy is due.

\section{Forster-CoOper.}

WE regret to announce the following deaths:

Dr. H. A. Buehler, geologist and director of the State Bureau of Geology and Mines, Missouri, on March 14, aged sixty-seven.

Dr. J. S. Bury, physician to the Manchester Royal Infirmary and a past-president of the Manchester Pathological Society and the Manchester Medical Society, on June 10, aged ninety-two.

Prof. J. Shaw Dunn, professor of pathology in the University of Glasgow, on June 10, aged sixty-one.

Dr. Robert A. Hatcher, emeritus professor of pharmacology and materia medica at Cornell University Medical College, on April 1, aged seventy-six.

Mr. E. Hatschek, the distinguished authority on colloid chemistry, on June 4, aged seventy-five.

Prof. Edward B. Mathews, emeritus professor of mineralogy and petrography at Johns Hopkins University, on February 4, aged seventy-four.

Prof. W. E. Tottingham, associate professor of agricultural chemistry in the University of Wisconsin, president in 1931 of the American Society of Plant Physiologists, on March 2, aged sixty-two.

Sir Cuthbert Wallace, Bart., K.C.M.G., C.B., president during $1935-38$ of the Royal College of Surgeons of England, on May 24. 